\title{
Effects of patients' motives in choosing a provider on determining the type of medical institution
}

\author{
This article was published in the following Dove Press journal: \\ Patient Preference and Adherence \\ Number of times this article has been viewed
}

\author{
Yeon-Yong Kim' \\ Jaekyoung $\mathrm{Bae}^{2}$ \\ Jin-Seok Lee ${ }^{2,3}$ \\ 'Big Data Steering Department, \\ National Health Insurance Service, \\ Wonju, ${ }^{2}$ Department of Health \\ Policy and Management, Seoul \\ National University College of \\ Medicine, ${ }^{3}$ Institute of Health Policy \\ and Management, Medical Research \\ Center, Seoul National University, \\ Seoul, Republic of Korea
}

\begin{abstract}
Background: Primary care is relatively weak in the Republic of Korea. As the referral system is not well established, patients can freely choose from among clinics, hospitals, and tertiary hospitals This study was conducted to determine the factors influencing patients' choice of providers.

Methods: A survey was conducted of 999 Korean adults aged 19-59 years. An exploratory factor analysis was performed on nine factors influencing their motives in choosing a medical provider. The factors derived from this analysis and the types of medical institutions were used as the independent and dependent variables, respectively, in logistic regression analysis. Adjustments were made for region, gender, age, educational level, income, type of insurance, and chronic diseases.

Results: The results showed that patients preferred clinics when considering the importance of accessibility, staff kindness, and patient-centeredness; they preferred hospitals when considering cleanliness; and tertiary hospitals when considering the reputation and structural factors. When considering structural factors, clinics and hospitals were less preferred; however tertiary hospitals were less preferred when considering accessibility, staff kindness, and patient-centeredness.

Conclusion: It is necessary to provide more accessible and patient-centered services in order to strengthen the primary health care role of clinics. In addition, efforts are needed to improve the quality of health care of tertiary hospitals in order to meet patient expectations.
\end{abstract}

Keywords: delivery of health care, patient preference, primary health care, factor analysis

\section{Background}

In the Republic of Korea, patients are free to choose their medical provider from among clinics, hospitals, and tertiary hospitals. The functional differences between these facilities are unclear; therefore, there is an increased need to strengthen primary care centered on clinics. ${ }^{1,2}$ Starfield ${ }^{3}$ evaluated the elements composing the primary health care system of a country and reported that the lower the level of primary health care, the more it affected health outcomes, health care expenditures, and patient satisfaction. A study that applied the same criteria in Korea revealed a low level of primary care; ${ }^{4}$ during the Middle East respiratory syndrome (MERS) outbreak in 2015, patients' ability to report directly to a tertiary hospital without undergoing a proper referral process was identified as the main cause of MERS contamination. ${ }^{5}$ One study found that up to $85 \%$ of patients chose tertiary hospitals over primary care institutions such as clinics, mostly based on the preferences of patients with chronic diseases such as hypertension. ${ }^{6}$ In 2009, the Ministry of Health and Welfare increased outpatient outof-pocket payments for tertiary hospitals to promote the utilization of clinics, but the effect was found to be partial. ${ }^{7}$

Although the choice of providers is unrestricted in Korea, there are few studies from the consumer's perspective, except for a few studies showing that quality and 
satisfaction affect patient revisitation. ${ }^{8,9}$ In Korea's referral system, the factors that affect the use of each type of medical institution are not well identified. Even in other countries, patients' choice of providers is an interesting topic. A largescale study was conducted in the UK to improve the long wait times. ${ }^{10}$ In addition, the motives in choosing a provider are important with regard to efficiency. ${ }^{11}$ Although studies on patient motives in choosing a provider are mostly related to their choice of primary care clinic or general practitioner, ${ }^{12,13}$ they also include topics such as obstetrics-gynecology, ${ }^{14,15}$ surgery, ${ }^{16,17}$ and public-private institutions. ${ }^{18}$

Patient choice in health care utilization is an important emerging topic in health management, including aspects such as self-care and consumer rights (informed choice). ${ }^{19,20}$ Although provider policy is important in improving the health care delivery system, considering the consumer's perspective is also necessary. ${ }^{21}$ The present study investigated the patients' choice of providers and the consequent type of medical institution; these results will form the basis for improving the health care delivery system and strengthening primary health care.

\section{Methods}

\section{Survey}

A survey was conducted of 1,000 Korean adults aged 19-59 years. The samples were selected using a proportionate quota sampling based on gender, age, and region. Weightings were assigned after the survey and used in the analysis. The survey was conducted using an Internet survey system from the research firm Research \& Research, Inc., which has a certified quality management system. The survey period was from August 28, 2015, to September 4, 2015. The variables included gender, age, region, educational level, income, type of insurance, chronic diseases, patient motives in choosing a provider, and type of medical institution used to obtain health care for chronic diseases. A total of 999 participants were included in the analysis after excluding one missing data.

\section{Factor analysis of patients' motives in choosing a provider}

In assessing the motives for choosing a provider, nine factors were selected based on a literature review, 9,10,19 including 1) distance and transportation time; 2) cleanliness; 3) the most modern facilities and equipment; 4) reputation; 5) administrative simplicity; 6) medical cost; 7) staff kindness; 8) waiting time; and 9) public reporting of quality. Each factor's degree of importance was measured using a 4-point scale. Exploratory factor analysis was conducted on the survey results to evaluate the validity of each question. Principal axis factoring was used as an estimation method; the number of factors was determined using Kaiser's criteria (eigenvalue $>1$ ). The squared multiple correlations of each variable with all other variables were used as the prior communality estimates. If the number of factors satisfying Kaiser's criteria was insufficient, it was determined using a cumulative variation. Items with $\geq 0.4$ factor loading were included as the final factors. Varimax and Cronbach's alpha were used as the rotation method and to measure the reliability of the exploratory factor analysis, respectively.

\section{Logistic regression of the types of medical institutions}

The types of medical institutions were determined by assessing which institution the participants used from among clinics, hospitals, and tertiary hospitals if they had a chronic disease such as hypertension or diabetes mellitus. Logistic regression analysis was performed using the factors obtained from the factor analysis as the independent variables and the type of medical institution as the dependent variable. A new factor was used in the analysis based on the average value of the existing factors. Region, gender, age, educational level, income status, type of insurance, and chronic diseases were adjusted.

SAS version 9.4 was used to perform the statistical analysis. This study received approval from the Institutional Review Board of Seoul National University Hospital (IRB No: 1508-064-094). The survey was conducted after obtaining online informed consent from all participants.

\section{Results}

\section{General characteristics}

Table 1 lists the general characteristics of the participants. The majority were men in their 40s from Incheon city and Gyeonggi-do regions. Most were insured employees, had received graduate school education, and had incomes between 2 and 4 million Korean Won. Regarding their motives in choosing a provider, the participants considered the most modern facilities and equipment as the most important factor, followed by medical cost and reputation.

Regarding the types of medical institutions, participants preferred hospitals over clinics and tertiary hospitals. Depending on the region, participants preferred tertiary hospitals in Seoul and hospitals in other regions. Participants in their 20s preferred tertiary hospitals, while those in their 30 s and $\geq 40$ years of age preferred hospitals and clinics, respectively. Insured patients preferred hospitals, while medical aid patients preferred tertiary hospitals. 
Table I General characteristics according to the preferred institution type (weighted frequencies and percentages)

\begin{tabular}{|c|c|c|c|c|}
\hline \multirow[t]{3}{*}{ Characteristics } & \multirow[t]{2}{*}{$\begin{array}{l}\text { Weighted } \\
\text { frequency }\end{array}$} & \multicolumn{3}{|c|}{$\begin{array}{l}\text { Preferred institution type for } \\
\text { chronic diseases }\end{array}$} \\
\hline & & Clinic & Hospital & $\begin{array}{l}\text { Tertiary } \\
\text { hospital }\end{array}$ \\
\hline & $\mathbf{n}$ & n (\%) & n (\%) & n (\%) \\
\hline Total & 999 & $3 I I(3 I . I)$ & $374(37.4)$ & $314(31.5)$ \\
\hline \multicolumn{5}{|l|}{ Region } \\
\hline Seoul & 207 & 67 (32.6) & $64(31.0)$ & $75(36.5)$ \\
\hline Incheon/Gyeonggi & 306 & $84(27.6)$ & $117(38.3)$ & $105(34.2)$ \\
\hline Daejon/Chungcheong & 99 & $34(34.3)$ & $35(35.4)$ & $30(30.3)$ \\
\hline Gwangju/Jeolla & 95 & $24(25.6)$ & $42(44.6)$ & $28(29.8)$ \\
\hline Daegu/Gyeongbuk & 97 & $34(34.8)$ & $43(44.8)$ & $20(20.5)$ \\
\hline Busan/Ulsan/ & 156 & $55(35.1)$ & $57(36.2)$ & $45(28.7)$ \\
\hline \multicolumn{5}{|l|}{ Gyeongnam } \\
\hline Gangwon/Jeju & 39 & $12(31.5)$ & 15 (39.2) & II (29.2) \\
\hline \multicolumn{5}{|l|}{ Gender } \\
\hline Men & 513 & $156(30.3)$ & $188(36.6)$ & 170 \\
\hline Women & 486 & $155(32.0)$ & $186(38.3)$ & I 44 (29.7) \\
\hline \multicolumn{5}{|l|}{ Age (years) } \\
\hline $20-29$ & 229 & 42 (18.2) & $83(36.4)$ & $104(45.4)$ \\
\hline $30-39$ & 240 & $60(25.0)$ & $93(38.6)$ & $87(36.4)$ \\
\hline $40-49$ & 275 & $106(38.6)$ & $101(36.8)$ & $68(24.7)$ \\
\hline $50+$ & 255 & $103(40.4)$ & $97(37.9)$ & $55(21.6)$ \\
\hline \multicolumn{5}{|l|}{ Insurance type } \\
\hline Self-employed insured & 359 & $105(29.2)$ & I $37(38.1)$ & $118(32.8)$ \\
\hline Employee insured & 564 & $187(33.2)$ & $210(37.2)$ & $167(29.6)$ \\
\hline Medical aid & 76 & $19(24.6)$ & $28(36.3)$ & $30(39.1)$ \\
\hline \multicolumn{5}{|l|}{ Education } \\
\hline Under high school & 177 & $63(35.4)$ & $63(35.4)$ & $52(29.3)$ \\
\hline University & 730 & $225(30.8)$ & $280(38.3)$ & $226(30.9)$ \\
\hline Graduate school & 92 & $24(25.8)$ & $32(34.5)$ & $37(39.8)$ \\
\hline \multicolumn{5}{|c|}{ Income (million won per month) } \\
\hline$<200$ & 132 & $46(34.7)$ & $47(35.9)$ & $39(29.5)$ \\
\hline 200-399 & 382 & $110(28.8)$ & |5| (39.5) & $12 \mid(3 \mid .7)$ \\
\hline $400-599$ & 333 & $103(31.1)$ & $123(36.9)$ & $107(32.1)$ \\
\hline$\geq 600$ & 153 & $52(33.9)$ & $53(34.9)$ & $48(31.2)$ \\
\hline \multicolumn{5}{|l|}{ Chronic disease } \\
\hline Yes & 477 & $160(33.5)$ & $173(36.2)$ & $144(30.3)$ \\
\hline No & 522 & I5I (28.9) & $201(38.5)$ & $170(32.6)$ \\
\hline \multicolumn{5}{|c|}{ Hospital choice factor (most important factor) } \\
\hline $\begin{array}{l}\text { Distance and } \\
\text { transportation time }\end{array}$ & 277 & II 4 (4I.2) & $98(35.5)$ & $64(23.3)$ \\
\hline Cleanliness & 223 & $65(29.4)$ & $93(41.7)$ & $65(28.9)$ \\
\hline $\begin{array}{l}\text { Most modern facility } \\
\text { and equipment }\end{array}$ & 385 & $96(24.8)$ & $128(33.2)$ & $162(42.0)$ \\
\hline Reputation & 314 & $96(30.5)$ & $95(30.3)$ & $123(39.2)$ \\
\hline Administrative simplicity & 201 & $78(39.0)$ & $68(33.9)$ & $54(27.1)$ \\
\hline Medical cost & 325 & $100(30.9)$ & $118(36.3)$ & $107(32.8)$ \\
\hline Staff kindness & 279 & $104(37.3)$ & $98(35.0)$ & $77(27.7)$ \\
\hline Waiting time & 243 & $96(39.6)$ & $89(36.7)$ & $57(23.7)$ \\
\hline $\begin{array}{l}\text { Public reporting of } \\
\text { quality }\end{array}$ & 275 & $85(31.0)$ & $83(30.2)$ & $107(38.8)$ \\
\hline
\end{tabular}

Abbreviation: $n$, number.

Finally, participants with higher educational levels preferred tertiary hospitals, while others preferred hospitals.

Regarding the motives in choosing a provider, the following factors were considered most important: "distance and time of transportation", "administrative simplicity", "staff kindness", and "waiting time" for clinics; "cleanliness" and "medical cost" for hospitals; and "the most modern facilities and equipment", "reputation", and "public reporting of quality" for tertiary hospitals.

\section{Factor analysis results}

Table 2 presents the results of the factor analysis of the motives for choosing a provider. As only one factor had an eigenvalue $>1$, the number of factors was determined based on $100 \%$ cumulative variation. The factor loading values of administrative simplicity, waiting time, distance and transportation time, medical cost, and staff kindness in factor 1 were $>0.4$, which were included as factors with communality. The factor loading of the most modern facilities and equipment, public's reporting of quality, reputation, and cleanliness in factor 2 were included as factors with communality. The Cronbach's alpha, which was the basis of reliability of each factor, was calculated. The coefficients of the Cronbach's alpha of factors 1 and 2 were 0.82 and 0.76 , respectively.

\section{Logistic regression results}

The factor analysis results revealed two factors influencing the choice of provider. Factors 1 and 2 were classified as accessibility and patient-centeredness and quality of health care, respectively.

Logistic regression analysis was conducted using the derived factors and the type of medical institution as the independent and dependent variables, respectively (Table 3). When considering accessibility and patient-centeredness as

Table 2 Factor loadings of the varimax rotation in the factor analysis

\begin{tabular}{llll}
\hline Factor & Hospital choice factor & $\begin{array}{l}\text { Factor I } \\
\text { (factor } \\
\text { loading) }\end{array}$ & $\begin{array}{l}\text { Factor 2 } \\
\text { (factor } \\
\text { loading) }\end{array}$ \\
\hline Factor I & Administrative simplicity & 0.67 & 0.29 \\
& Waiting time & 0.67 & 0.27 \\
& Distance and transportation time & 0.59 & 0.09 \\
& Medical cost & 0.58 & 0.38 \\
& Staff kindness & 0.56 & 0.45 \\
Factor 2 & Most modern facility and equipment & 0.14 & 0.68 \\
& Public reporting of quality & 0.23 & 0.60 \\
& Reputation & 0.25 & 0.59 \\
& Cleanliness & 0.40 & 0.51 \\
Eigenvalue (before rotation) & 3.58 & 0.58 \\
Proportion (before rotation) & 0.98 & 0.16 \\
Variance explained (after rotation) & 2.19 & 1.96
\end{tabular}

Note: The coefficients of Cronbach's alpha of factor I (administrative simplicity, waiting time, distance and transportation time, medical cost, and staff kindness) and factor 2 (most modern facility and equipment, public reporting of quality, reputation, and cleanliness) were 0.82 and 0.76 , respectively. 
Table 3 Logistic regression analysis of factors affecting the choice of hospital

\begin{tabular}{|c|c|c|c|c|c|c|}
\hline \multirow[t]{2}{*}{ Variable } & \multicolumn{2}{|l|}{ Clinic } & \multicolumn{2}{|c|}{ Hospital } & \multicolumn{2}{|c|}{ Tertiary hospital } \\
\hline & $\begin{array}{l}\text { Odds } \\
\text { ratio }\end{array}$ & $95 \% \mathrm{Cl}$ & $\begin{array}{l}\text { Odds } \\
\text { ratio }\end{array}$ & $95 \% \mathrm{Cl}$ & $\begin{array}{l}\text { Odds } \\
\text { ratio }\end{array}$ & $95 \% \mathrm{Cl}$ \\
\hline \multicolumn{7}{|l|}{ Hospital choice factor } \\
\hline Accessibility and patient centeredness & $3.29 *$ & $2.28-4.74$ & $1.37 *$ & $1.01-1.86$ & $0.21 *$ & $0.15-0.31$ \\
\hline Quality of health care & $0.37 *$ & $0.26-0.52$ & $0.61 *$ & $0.45-0.82$ & $5.32^{*}$ & $3.62-7.84$ \\
\hline \multicolumn{7}{|l|}{ Region (ref: Seoul) } \\
\hline Incheon/Gyeonggi & 0.81 & $0.54-1.22$ & 1.39 & $0.95-2.04$ & 0.86 & $0.57-1.29$ \\
\hline Daejon/Chungcheong & 1.28 & $0.74-2.20$ & 1.33 & $0.79-2.23$ & $0.54 *$ & $0.30-0.95$ \\
\hline Gwangju/Jeolla & 0.77 & $0.43-1.36$ & $1.82 *$ & $1.09-3.02$ & 0.65 & $0.37-1.15$ \\
\hline Daegu/Gyeongbuk & 1.16 & $0.68-2.00$ & $1.83 *$ & $1.11-3.04$ & $0.39 *$ & $0.21-0.72$ \\
\hline Busan/Ulsan/Gyeongnam & 1.17 & $0.74-1.87$ & 1.28 & $0.82-2.00$ & 0.64 & $0.39-1.04$ \\
\hline Gangwon/Jeju & 0.99 & $0.44-2.20$ & 1.49 & $0.72-3.08$ & 0.55 & $0.23-1.32$ \\
\hline \multicolumn{7}{|l|}{ Gender (ref: women) } \\
\hline Men & 0.99 & $0.74-1.33$ & 0.91 & $0.70-1.19$ & 1.12 & $0.83-1.52$ \\
\hline \multicolumn{7}{|l|}{ Age (ref: $20-29$ years), years } \\
\hline $30-39$ & 1.36 & $0.84-2.19$ & 1.09 & $0.74-1.63$ & 0.77 & $0.5 \mathrm{I}-\mathrm{I} .18$ \\
\hline $40-49$ & $2.60 *$ & $1.66-4.09$ & 1.03 & $0.69-1.52$ & $0.43^{*}$ & $0.28-0.67$ \\
\hline $50+$ & $2.77^{*}$ & $1.74-4.43$ & 1.10 & $0.73-1.66$ & $0.36 *$ & $0.23-0.57$ \\
\hline Chronic disease (ref: no) & 1.01 & $0.75-1.36$ & 0.92 & $0.70-1.21$ & 1.09 & $0.80-1.49$ \\
\hline \multicolumn{7}{|c|}{ Insurance type (ref: the employee insured) } \\
\hline Self-employed insured & 0.98 & $0.7 I-1.35$ & 1.08 & $0.8 \mathrm{I}-1.45$ & 0.96 & $0.69-1.34$ \\
\hline Medical aid & 0.81 & $0.43-1.50$ & 0.99 & $0.58-1.70$ & 1.26 & $0.70-2.27$ \\
\hline \multicolumn{7}{|l|}{ Education (ref: graduate school) } \\
\hline Under high school & 1.28 & $0.69-2.38$ & 0.96 & $0.55-1.69$ & 0.88 & $0.48-1.63$ \\
\hline University & 1.36 & $0.80-2.30$ & 1.13 & $0.7 I-1.8 I$ & 0.68 & $0.4 I-I .12$ \\
\hline \multicolumn{7}{|c|}{ Income, million won per month (ref: $\geq 600$ ) } \\
\hline$<200$ & 0.94 & $0.53-1.66$ & 0.92 & $0.54-1.57$ & 1.08 & $0.53-1.97$ \\
\hline $200-399$ & 0.79 & $0.5 I-1.23$ & I.II & $0.74-1.68$ & 1.11 & $0.70-1.76$ \\
\hline $400-599$ & 0.72 & $0.47-1.12$ & 1.03 & $0.68-1.55$ & 1.33 & $0.84-2.09$ \\
\hline
\end{tabular}

Notes: The odds ratio was adjusted for all other variables. ${ }^{*} p<0.05$.

Abbreviations: $\mathrm{Cl}$, confidence interval; ref, reference.

an important factor, the probabilities of choosing clinics, hospitals, and tertiary hospitals were $3.29,1.37$, and 0.21 times higher than those for the other types of medical institutions, respectively. When considering quality of health care, the probabilities of choosing clinics, hospitals, and tertiary hospitals were $0.37,0.61$, and 5.32 times higher, respectively.

\section{Discussion}

Factor and logistic regression analyses were performed on the patients' motives in choosing a provider and the consequent determination of the type of medical institution. The results showed that patients preferred clinics and hospitals when considering the importance of accessibility and patient-centeredness and tertiary hospitals when considering the quality of health care. However, when considering accessibility and patient-centeredness, the participants less often preferred tertiary hospitals; similarly, when considering the quality of health care, they less preferred clinics and hospitals.
In previous studies, functional differences based on the type of medical institution were not well understood because the same medical services are provided in clinics, hospitals, and tertiary hospitals. ${ }^{6}$ In the present study, the functional differences were indirectly identified by assessing the various motives for choosing a provider. The expected roles and patient needs varied depending on the type of institution. Each type of patient expected different types of medical services: patients visiting clinics and hospitals expected kind and patient-centered services, while those visiting tertiary hospitals expected a good reputation and structural factors (the most modern facilities and equipment and public reporting of quality). The health care public service evaluation implemented in Korea includes hospital accreditation and itemized evaluations of the appropriateness of individual services, which target the structure, process, and outcomes. However, the structure had the greatest influence on the evaluation results, ${ }^{22}$ based on the patients' preferences. ${ }^{23}$ Therefore, modern facility and equipment and the public 
reporting of quality were both classified as "quality of health care".

Regarding the characteristics of primary health care, patient-centeredness has been recently proposed as an essential element along with the first visit, continuity, comprehensiveness, and coordination. ${ }^{3,24}$ One study indicated that patient-centered care is efficient by reducing unnecessary diagnostic tests while improving clinical outcomes. ${ }^{25}$ In addition, the World Health Organization ${ }^{26}$ also included responsiveness as an important factor that influences health. Continuity of care, accessibility, and patient-centeredness, which are vital in the treatment of chronic diseases such as hypertension and diabetes mellitus, are primary health care characteristics that positively influence health outcomes and health care costs. ${ }^{3}$

A clean environment also influences patient perception of quality of care, especially for infectious diseases. ${ }^{27}$ Structural factors and reputation significantly affect health care outcomes by utilizing economies of scale; the volume-outcome effect is closely related to the quality of surgeries and rare diseases. ${ }^{28}$ Although patients who selected hospitals and tertiary hospitals also considered the quality of care, these types of institutions are more appropriate for the treatment of infectious diseases, acute complication of chronic disease (such as myocardial infarction and cerebrovascular disease), and surgeries rather than for the management of chronic diseases.

This study investigated the factors that influence the type of institutions based on patient motives in choosing a provider, which has not previously been sufficiently examined. The significance of this study lies in its use of a survey to identify functional differences between institutions, which have not previously been sufficiently understood in analyzing the current situation in Korea. This study has some limitations because of its cross-sectional design: information to determine causality was lacking and the determination of the type of medical institution was based on a survey rather actual data. It is also possible that the short survey period may have affected the results. This study was also limited in evaluating how the motives in choosing a provider and the type of medical institution affected the clinical outcome, which indicates the need for further research.

\section{Conclusion}

When applying research results to policy, it is necessary to provide more accessible and patient-centered services in order to strengthen the primary health care role of clinics. In addition, efforts are needed to improve the quality of health care of tertiary hospitals in order to meet patient expectations.
Finally, the results of this study form a basis for improving the health care delivery system in Korea.

\section{Acknowledgment}

This study was supported by the Ministry of Health and Welfare of the Republic of Korea.

\section{Author contributions}

YYK and JSL designed the study. JB conducted the literature review. All authors contributed toward data analysis, drafting and critically revising the paper and agree to be accountable for all aspects of the work.

\section{Disclosure}

The authors report no conflicts of interest in this work.

\section{References}

1. Park KD. Direction of health care and health insurance system reform to strengthen primary care: comparative analysis of Korea, Japan and Taiwan. J Korean Acad Fam Med. 2003;24:328-345.

2. Ock MS, Kim JE, Jo MW, Lee HJ, Kim HJ, Lee JY. Perceptions of primary care in Korea: a comparison of patient and physician focus group discussions. BMC Fam Pract. 2014;15:178.

3. Starfield B. Primary Care: Balancing Health Needs, Services, and Technology. Cary, NC: Oxford University Press; 1998.

4. Ahn SH. Assessment of primary care level in Korea and comparison with the developed countries. J Korean Acad Fam Med. 2001;22: 483-497.

5. Ki M. 2015 MERS outbreak in Korea: hospital-to-hospital transmission. Epidemiol Health. 2015;37:e2015033.

6. Lee JY, Jo MW, Yoo WS, Kim HJ, Eun SJ. Evidence of a broken healthcare delivery system in Korea: unnecessary hospital outpatient utilization among patients with a single chronic disease without complications. J Korean Med Sci. 2014;29(12):1590-1596.

7. Kim HJ, Kim YH, Kim HS, Woo JS, Oh SJ. The impact of outpatient coinsurance rate increase on outpatient healthcare service utilization in tertiary and general hospital. Health Policy Manag. 2013;23:19-34.

8. Choi KS, Cho WH, Lee S, Lee H, Kim C. The relationships among quality, value, satisfaction and behavioral intention in health care provider choice: a South Korean study. J Bus Res. 2004;57:913-921.

9. Yoon SJ, Yu SH, Kim YH, Lee JJ. A study for the factors on choosing hospitals and patients satisfaction between geriatric hospitals and general hospitals. Korea Soc Hosp Admin. 2003;9:46-75.

10. Burge P, Devin N, Appleby J, Rohr C, Grant J. Do patients always prefer quicker treatment? A discrete choice analysis of patients' stated preferences in the London Patient Choice Project. Appl Health Econ Health Policy. 2004;3:183-194.

11. Sheiman I, Shishkin S, Markelova H. Opportunities and limitations of patient choice: the case of the Russian Federation. Health Policy Plan. 2014;29(1):106-114.

12. Fung C, Elliott M, Hays R, et al. Patients' preferences for technical versus interpersonal quality when selecting a primary care physician. Health Serv Res. 2005;40:957-977.

13. Gupta D, Wang L. Revenue management for a primary-care clinic in the presence of patient choice. Oper Res. 2008;56:576-592.

14. Plunkett B, Kohli P, Milad M. The importance of physician gender in the selection of an obstetrician or a gynecologist. Am J Obstet Gynecol. 2002;186(5):926-928.

15. Schnatz PF, Murphy JL, O'Sullivan DM, Sorosky JI. Patient choice: comparing criteria for selecting an obstetrician-gynecologist based on image, gender, and professional attributes. Am J Obstet Gynecol. 2007;197(5):548.e1-e7. 
16. Lavelle K, Sowerbutts AM, Bundred N, et al. Is lack of surgery for older breast cancer patients in the UK explained by patient choice or poor health? A prospective cohort study. Br J Cancer. 2014;110(3):573.

17. Moodie JJ, Masood I, Tint N, Rubinstein M, Vernon SA. Patients' attitudes towards trainee surgeons performing cataract surgery at a teaching hospital. Eye. 2008;22:1183-1186.

18. Andaleeb SS. Public and private hospitals in Bangladesh: service quality and predictors of hospital choice. Health Policy Plan. 2000; 15(1):95-102.

19. Appleby J, Harrison A, Devlin NJ. What is the Real Cost of More Patient Choice? London: The King's Fund; 2003.

20. Victoor A, Delnoij DM, Friele RD, Rademakers JJ. Determinants of patient choice of healthcare provider: a scoping review. BMC Health Serv Res. 2012;12:272.

21. Robinson JC. Managed consumerism in health care. Health Aff. 2005;24:1478-1479.

22. Kunkel S, Rosenqvist U, Westerling R. The structure of quality systems is important to the process and outcome, an empirical study of 386 hospital departments in Sweden. BMC Health Serv Res. 2007;7:104.
23. Rademakers J, Delnoij D, de Boer D. Structure, process or outcome: which contributes most to patients' overall assessment of healthcare quality? BMJ Qual Saf. 2011;20:326-331.

24. Schoen C, Osborn R, Huynh PT, Doty M. Primary care and health system performance: adults' experiences in five countries. Health Aff. 2004;23:W4-W487.

25. Oates J, Weston WW, Jordan J. The impact of patient-centered care on outcomes. Fam Pract. 2000;49:796-804.

26. World Health Organization. The World Health Report 2000: Health Systems: Improving Performance. Geneva: World Health Organization; 2000 .

27. Liyanage C, Egbu C. Controlling healthcare associated infection (HAI) and the role of facilities management in achieving 'quality' in healthcare: a three dimensional view. Facilities. 2005;23:5-6.

28. Halm EA, Lee $\mathrm{C}$, Chassin MR. Is volume related to outcome in health care? A systematic review and methodologic critique of the literature. Ann Intern Med. 2002;137(6):511-520.

\section{Publish your work in this journal}

Patient Preference and Adherence is an international, peer-reviewed, open access journal that focuses on the growing importance of patient preference and adherence throughout the therapeutic continuum. Patient satisfaction, acceptability, quality of life, compliance, persistence and their role in developing new therapeutic modalities and compounds to optimize clinical outcomes for existing disease states are major areas of interest for the journal. This journal has been accepted for indexing on PubMed Central. The manuscript management system is completely online and includes a very quick and fair peer-review system, which is all easy to use. Visit http://www. dovepress.com/testimonials.php to read real quotes from published authors. 